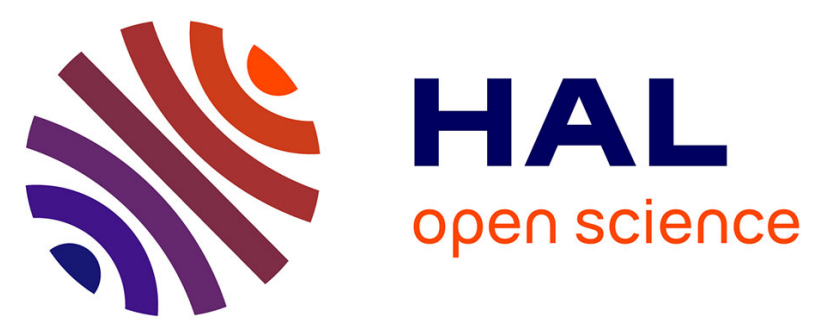

\title{
Depression is associated with some patient-perceived cosmetic changes, but not with radiotherapy-induced late toxicity, in long-term breast cancer survivors.
}

Paul Brunault, Isabelle Suzanne, Magdalena Trzepidur-Edom, Pascal Garaud, Gilles Calais, Alain Toledano, Vincent Camus

\section{To cite this version:}

Paul Brunault, Isabelle Suzanne, Magdalena Trzepidur-Edom, Pascal Garaud, Gilles Calais, et al.. Depression is associated with some patient-perceived cosmetic changes, but not with radiotherapyinduced late toxicity, in long-term breast cancer survivors.: Depression-associated factors in long-term breast cancer survivors. Psycho-Oncology, 2013, 22 (3), pp.590-7. 10.1002/pon.3038 . inserm00686277

\section{HAL Id: inserm-00686277 https://www.hal.inserm.fr/inserm-00686277}

Submitted on 9 Apr 2012

HAL is a multi-disciplinary open access archive for the deposit and dissemination of scientific research documents, whether they are published or not. The documents may come from teaching and research institutions in France or abroad, or from public or private research centers.
L'archive ouverte pluridisciplinaire HAL, est destinée au dépôt et à la diffusion de documents scientifiques de niveau recherche, publiés ou non, émanant des établissements d'enseignement et de recherche français ou étrangers, des laboratoires publics ou privés. 
Title: Depression is associated with some patient-perceived cosmetic changes, but not with radiotherapy-induced late toxicity, in long-term breast cancer survivors

Authors: Paul Brunault ${ }^{1}$, Isabelle Suzanne ${ }^{1}$, Magdalena Trzepidur-Edom ${ }^{1}$, Pascal Garaud $^{1}$, Gilles Calais ${ }^{1,2}$, Alain Toledano ${ }^{3}$, Vincent Camus ${ }^{1,2,4}$

${ }^{1}$ CHRU de Tours, Tours, France

${ }^{2}$ Université François Rabelais de Tours, Tours, France

${ }^{3}$ Hôpital Américain de Paris-Clinique Hartmann, Neuilly sur Seine, France

${ }^{4}$ UMR INSERM U930 \& CNRS ERL 3106, Tours, France

Corresponding author:

Paul Brunault

e-mail address: paul.brunault@gmail.com

Telephone number: $+33-247-47478043$

Fax number: +33-247-478402

Short title: Depression-associated factors in long-term breast cancer survivors

CONFLICT OF INTEREST DISCLOSURE: The authors declare that they have no conflict of interest. 


\section{ABSTRACT}

\section{Objective:}

Though depression is prevalent in long-term breast cancer survivors (LTBCS; $\geq 5$ years since diagnosis), it is underdiagnosed and undertreated. A better understanding of factors associated with depression could improve depression screening, treatment and prevention in this population. Our study aimed to assess the link between patient and doctor ratings of breast cosmetic outcomes, late radiotherapy toxicity, and depression in LTBCS.

\section{Methods:}

In all, 214 patients recruited from the ARCOSEIN study were assessed for late radiotherapy toxicity (using the LENT-SOMA scale) and patient and doctor ratings of breast cosmetic outcomes (mean=6.7 years since the end of treatment). We reassessed 120 of these patients for depression (HAD) during a second wave of long-term assessment (mean $=8.1$ years since the end of treatment). We used univariate analyses and polytomous logistic regression analyses to predict the HAD depression, which was defined as follows: normal: 0-7 points and significant depression: $\geq 8$ points ( $8-10$ points: possible depression; $\geq 11$ points: probable depression).

Results:

The mean HAD depression score was $4.5 \pm 3.6$. 19.2\% of our population had significant depression, $6.7 \%$ with probable depression and $12.5 \%$ with possible depression. Significant depression was not associated with late radiotherapy toxicity or initial cancer-related variables. Patients with probable depression reported worse cosmetic outcomes than nondepressed patients in terms of perceived breast largeness $(p=.04)$, breast deformation $(p=.02)$, and changes in skin pigmentation $(p=.03)$.

\section{Conclusions:}

In LTBCS, depression seems to be more strongly associated with changes in some patients' perceived breast cosmetic outcome than late treatment toxicity or initial cancer-related variables.

KEYWORDS: cancer; oncology; long-term survivors; depression; body image 


\section{INTRODUCTION}

Breast cancer is the most common cancer among women worldwide, representing $23 \%$ of all cancers in this population [1]. The incidence of breast cancer is also high; it represents $22.9 \%$ of all estimated new cancer cases per year [1]. Because of better breast cancer detection and treatment, the breast cancer survival rate has dramatically improved since the 1980s, with current 5-year survival rates of $89 \%$ in the United States [2], 85\% in France [3], and $82 \%$ in the United Kingdom [4]. As the population ages, the number of breast cancer survivors increases, as does the number of long-term breast cancer survivors (LTBCS) [6]. LTBCS is defined by the American Cancer Society as a person who is still alive 5 years after diagnosis [5].

As the number of LTBCS increases in conjunction with better survival rates, the psychosocial outcomes (e.g., quality of life, depression, and anxiety) in this population have attracted clinical interest. Although most studies have reported that LTBCS experience an overall good quality of life [6-8], many survivors still experience substantial problems as a result of the cancer or its treatment [8]. Burgess et al. have reported a $15 \%$ prevalence of depression, anxiety, or both in the fifth year after breast cancer diagnosis [9]. There is evidence that depression in patients with cancer is a major predictor of distress and decreased quality of life for patients and their spouses, parents or other caregivers [10]. Because depression is underdiagnosed by oncologists and undertreated in patients with cancer [11-13], a better understanding of depression-associated factors would help clinicians to better screen for depression in LTBCS.

Many factors are related to psychological distress in women coping with breast cancer. These factors include facing a life-threatening illness, painful and impairing treatments, significant role changes and issues related to body image [14]. According to Helms et al. [14], the association between issues related to body image and psychological distress has been less studied than other factors. The concept of body image is multidimensional because it encompasses both perceptual and subjective components [15]. Body image can be defined as "the picture we have in our minds of the size, shape and form of our bodies; and to our feelings concerning these characteristics and our constituent body parts" [16]. The dimensions of body experiences are highly subjective and do not necessarily reflect objective reality [15]. According to previous body image research in psychology, body image disturbances may lead to depressive symptoms, poor self-esteem and social anxiety [14].

After breast cancer, one aspect of body image might be investigated using assessment of breast cosmesis, which incorporates the total sum of the breast's appearance after treatment and an esthetic judgement of the breast's appearance [17]. Body image might be assessed using objective evaluation (i.e., physician assessed), which relates to physician perceptions of breast cosmetic result itself, and subjective evaluation (i.e., patient assessed), which depends on how this objective breast cosmetic result is perceived and felt by the patient $[15,16,18]$. One potential difference between objective and subjective body image ratings is that the latter depend on the concern about body image, which pertains how much the body image matters to the patients [19]. In breast cancer survivors, both objective and subjective body image evaluations are needed to assess breast cosmetic outcomes [18].

After breast-conserving surgery, which is considered the least disfiguring surgical option after breast cancer [20], the esthetic outcome varies widely, and patients and physicians report alterations in breast cosmetic outcomes [17,18,21]. Unsatisfactory cosmetic results following breast-conserving surgery may contribute to depression [14,22,23]. In a population of breast cancer patients with a mean follow-up of 3.3 years, Al Ghazzal et al. [23] found a significant association between depression and breast retraction, nipple deviation and the overall cosmetic outcome of the treated breast. However, in that study, the breast cosmesis 
evaluation was performed by physicians and not by patients. In a population with follow-up of 1 to 4 years after surgery, Waljee et al. [24] found that women with pronounced perceived breast asymmetry were more likely to exhibit depressive symptoms than women with minimal asymmetry. However, this study included patients with a maximum follow-up of 4 years, whereas breast cosmetic outcomes may vary until at least 5 years after treatment [18]. Moreover, this study did not also assess the physicians' breast cosmetic outcome ratings. To our knowledge, no study has focused on the association between depression and the patient and physician evaluations of cosmetic outcomes in LTBCS.

Following breast cancer, use of radiotherapy has also been hypothesized to impact long-term breast cosmetic outcome [25]. Indeed, radiotherapy can lead to a broad range of late toxicity effects (e.g., edema, fibrosis) [26], which are radiotherapy-related adverse effects occuring at least 6 months after radiotherapy completion. To our knowledge, no study has focused on the association between depression and late radiotherapy toxicity in LTBCS.

Our cohort study aimed to assess the association between depression and the patient and doctor evaluations of breast cosmetic outcomes in LTBCS. We hypothesized that depression is associated with worse patients' and doctors' breast cosmetic outcome evaluations for the treated breast. As a secondary objective, our study also aimed to assess the link between late radiotherapy toxicity and long-term depression. We hypothesized that the existence of late radiotherapy toxicity leads to higher depression levels.

\section{METHODS}

\section{Participants and procedures}

Potentially eligible participants were recruited from the ARCOSEIN study [27,28]. The ARCOSEIN study was a multicenter French trial of breast cancer patients. It was initiated in 1996 and compared sequential treatment (chemotherapy followed by radiotherapy) with concurrent treatment (chemotherapy administered concurrently with radiotherapy) after breast-conserving surgery. The study found that the concurrent use of chemotherapy and radiotherapy was significantly associated with improved locoregional control rates, but it increased the incidence of late side effects and altered breast cosmesis [25,29].

The ARCOSEIN study (first assessment; T1) enrolled 716 patients with Stage I and II breast cancer who underwent breast-conserving surgery with axillary dissection between February 1996 and April 2000 [28]. The detailed chemotherapy and radiotherapy regimen used in the ARCOSEIN study has been described elsewhere [29].

In a second step of the study (second assessment; T2), all participants from the 5 larger institutions that participated in the ARCOSEIN study (297 patients from the French Radiotherapy departments of Tours, Avignon, Institut Curie-Paris, Besançon and Orleans) were invited by letter for a follow-up visit that focused on late toxicity and patient and doctor breast cosmesis assessments [25]. This visit was performed between July 2004 and April 2005 by an independent radiation oncologist. Of the 297 patients eligible for this second study, 214 (72\%) agreed to participate.

These 214 patients were potentially eligible for our study (third assessment; T3). We contacted these patients between October 2005 and December 2005 to ask them to participate to our study. Of the 214 potentially eligible patients, those who had no local recurrence or bilateral breast cancer or metastase(s) and returned completed questionnaires (i.e., no missing data for any sociodemographic characteristics, the Hospital Anxiety and Depression scale or the LENT-SOMA scale) were considered eligible.

\section{Measures}

Demographics and medical variables (T1 and T3 assessments) 
We obtained data, including age at the end of chemoradiotherapy treatment, time since the end of treatment, menopausal status, marital status and cancer-related variables at diagnosis (e.g., tumor stage, node status, tumor dimension and histological type) or during treatment (i.e., surgery type, concurrent or sequential administration of chemoradiotherapy, hormonotherapy), from the initial ARCOSEIN medical file (T1 assessment). Psychotropic drug use (anxiolytics or antidepressants) and psycho-oncological intervention rates (consultation with a psychiatrist or a psychologist) since the end of chemoradiotherapy treatment were retrospectively assessed (T3 assessment).

\section{Breast cosmetic outcomes and late treatment toxicity assessment (T2 assessment)}

Breast cosmetic outcomes were assessed by patients and doctors.

The patients were asked to complete the questionnaire developed by Hoeller et al. [30]. This questionnaire asked the patients to rate their overall cosmetic satisfaction using a 5point Likert response scale ranging from 1 ("excellent") to 5 ("very poor"). The patients were also asked to rate the difference between the treated and untreated breast in terms of scar visibility, change in skin pigmentation, breast largeness, breast deformation, breast size, breast firmness and nipple displacement. These questions employed a 5-point Likert response scale ranging from 1 ("none") to 5 ("very much"). These latter 8 items were treated as individual items because the factor analysis and Cronbach's internal consistency analysis did not support the theoretical grouping of these items into one, two or three subscales.

The doctors assessed cosmetic outcomes using two items that compared the treated and the untreated breast in terms of overall cosmetic satisfaction (an item developed by Fehlauer et al. [31] and scored with a 5-point Likert scale ranging from 1 ["excellent"] to 5 ["very poor"]) and scar visibility assessment (an item developed by Hoeller et al. [30] and ranging from 1 ["excellent"] to 5 ["very poor"]). To avoid bias, the physician in charge of the evaluation had no knowledge of the patient's assessment and was blinded to the type of chemoradiotherapy used (i.e., a sequential or concurrent regimen). Although the factor analysis did support the theoretical grouping of these items into one subscale, we treated them as individual items because Cronbach's internal consistency was poor $(\alpha=0.58)$.

The late toxicity assessment, which was blinded to treatment allocation (concurrent or sequential radiochemotherapy), was graded by an oncologist according to the LENT-SOMA scale and translated to French [32,33]. The LENT-SOMA scale assesses the following late toxicity symptoms: pain, edema, fibrosis, telangiectasia, arm lymphedema, atrophy or retraction and ulcer. The toxicity level for each of these symptoms was graded on a scale from 0 to 4 , with a higher grade indicating a higher level of late toxicity. In our study, toxicity was considered nonsignificant if it was graded 0 or 1 and significant if it was graded 2, 3 or 4 . In a previous study by Toledano et al. [25], these criteria allowed for very good interobserver reliability. These items were treated as individual items because the Kuder-Richardson coefficient for internal consistency was poor $(\mathrm{KR}-20=.51)$.

\section{Long-term depression (T3 assessment)}

We assessed long-term depression severity using the Hospital Anxiety and Depression scale (HAD) [34]. The HAD is a 14-item self-rating scale that assesses the severity of depression and anxiety, with each dimension receiving between 0 and 21. The HAD has been widely used and validated in cancer populations [35], has proven to have good reliability and validity [36], and is useful for screening for depression in LTBCS [37]. According to Bjelland et al. [36], an optimal balance between sensitivity and specificity is achieved when depression is defined by a score of 8 or above. In our study, there was significant depression when the depression score was 8 or above. According to Zigmond \& Snaith [34], scores of 11 or higher 
on the depression subscale indicate probable depression, scores between 8 and 10 indicate possible depression, and scores between 0 and 7 are considered normal.

\section{Statistical analysis}

For better clarity, statistical analyses we conducted were described in the corresponding subsections of the Results section. Analyses were conducted using the statistical packages StatView for Macintosh Version 5.0 (Abacus Concepts, SAS Institute, Cary, NC) and Systat 12 (Systat Software, San Jose, CA). All analyses were two-tailed. P values $<.05$ were considered statistically significant.

\section{Ethics}

The ARCOSEIN study was initially approved by each local institutional review board, and informed written consent was obtained from all patients. For our study, we obtained informed consent from each patient in accordance with the Helsinki declaration.

\section{RESULTS}

\section{Participants}

Figure 1 presents the study flow chart. Of the 214 potentially eligible patients, 138 returned a questionnaire, and 120 of these participants met our inclusion criteria. 18 participants $(13 \%)$ were excluded: $4(2.9 \%)$ because of recurrence and $14(10.1 \%)$ because of incomplete reporting.

\section{Sample characteristics}

The sociodemographic and clinical characteristics of the patients are presented in Table 1. All patients were LTBCS (the time since the end of chemoradiotherapy treatment ranged from 6.1 to 11.0 years) and initially underwent breast-conserving surgery with axillary dissection. The patient and doctor ratings of breast cosmetic outcomes are presented in Table 2.

The mean HAD depression score was $4.5 \pm 3$.6. Significant depression was observed in $19.2 \%(n=23)$ of the patients, including $6.7 \%$ with probable depression and $12.5 \%$ with possible depression. Of the patients who had significant depression, 61\% $(n=14)$ had used psychotropic treatment, and 35\% $(n=8)$ had consulted a psychiatrist or a psychologist since the end of chemoradiotherapy treatment.

\section{Factors associated with long-term depression}

We tested the association between socio-demographic, cancer-related variables, late treatment toxicity and depression status (i.e., significant depression or no depression) using the chisquared test, Fisher's exact test, the Kruskal-Wallis test or the Mann-Whitney U-test, depending on the variables involved (i.e., proportions or means). Because the chi-squared test must be considered only approximate when tables are larger than 2 x 2 with expected frequencies lower than 5, analyses were also conducted with depression as a continuous variable (Kruskal-Wallis test) in these cases.

\section{Sociodemographic and cancer-related variables}

Significant depression was not associated with age $(p=.29)$, menopausal status $(p=.44)$, or marital status $(p=.15)$. Long-term significant depression was not associated with any of the cancer-related variables at diagnosis or during treatment, including the following: time since treatment ended $(p=.59)$, tumor stage at diagnosis $(p=.11)^{1}$, node status $(p=.67)$, tumor

\footnotetext{
${ }^{1} p=.24$ for Kruskal-Wallis test
} 
dimension $(p=.83)$, histological type $(p=.25)^{2}$, surgery type $(p=.30)^{3}$, concurrent or sequential administration of chemoradiotherapy $(p=.12)$, or hormonotherapy $(p=.83)$.

\section{Late treatment toxicity}

There was no link between significant depression and the report of at least one late toxicity symptom $(p=.73)$. Depression was not associated with any of the significant late toxicity symptoms, including pain $(p=.34)$, edema $(p=.99)$, fibrosis $(p=.99)$, telangiectasia $(p=.99)$, arm lymphedema $(p=.58)$, atrophy or retraction $(p=.15)$ and ulcer.

\section{Breast cosmetic outcomes (Table 3)}

We examined the associations between patient and doctor ratings of breast cosmetic outcomes and depression using polytomous logistic regression analyses, depression being considered as a three-way categorical variable (i.e., probable depression, possible depression and no depression). All regression models included age, tumor stage at diagnosis, time since the end of treatment and marital status as covariates. No significant first-order interaction was identified.

\section{DISCUSSION}

In this study, which was conducted in LTBCS with an average follow-up of 8.1 years, patients with probable depression perceived their treated breasts to be larger, more deformed, and have worse skin pigmentation than nondepressed patients. We also found that late radiotherapy toxicity and initial cancer-related variables were not associated with long-term depression in LTBCS.

To our knowledge, this study is the first to show a significant link between long-term depression and patient breast cosmetic outcomes in LTBCS. The fact that breast largeness, breast deformation and change in skin pigmentation were the measures most strongly correlated with depression is intriguing. Body image encompasses both perceptual and subjective components [15], and in this study, we hypothesize that the perception of a deformed or larger breast relates to both dimensions, whereas the other items that we assessed would relate only to the perceptual dimension. According to Carver et al. [19], body image is often thought of in terms of physical appearance; however, body image may also pertain to integrity, wholeness, and normal functioning. In this study, we hypothesize that depression is more related to alterations in body image integrity, wholeness and functioning than physical appearance. Because being single was also found to be an independent risk factor for depression, we also hypothesize that concerns about body image, which may be higher among single women, also account for the increased risk for depression. Further prospective studies are needed to test these hypotheses.

These results are consistent with previous psychology research [14] and reports with shorter follow-up periods $[23,24]$. These data underscore the close relationship between body image alterations and long-term depression, which can occur more than 5 years after the breast cancer diagnosis and initial treatment. Because depression is associated with a systematic negative cognitive bias in information processing [38], we can assume that depressed individuals might respond negatively across all self-reported measures. Because depression is not associated with all items related to patient breast cosmesis, this hypothesis alone cannot explain all of our results. A different hypothesis may be proposed to explain these results. Waljee et al. [24] proposed that altered breast cosmesis could be a constant

\footnotetext{
${ }^{2} p=.36$ for Kruskal-Wallis test

${ }^{3} p=.61$ for Kruskal-Wallis test
} 
reminder of the disease and treatment process that impairs psychological adjustment after treatment.

Discrepancy between patient and doctors ratings is consistent with previous research [17] but intriguing. One explanation for this discrepancy might be that subjective ratings depend on concern about body image, whereas objective ratings do not. Patients with higher concern about body image might be at higher risk of discrepancy between objective and subjective body image ratings. Future studies should investigate the potential impact of concern about body image to explain this discrepancy. Our results also confirm that a combination of objective and subjective evaluations are needed to assess breast cosmetic outcome.

In another important finding of our study, the LTBCS-related depression risk does not seem to be associated with late radiotherapy toxicity symptoms or with the initial chemoradiotherapy treatment type. Our results are consistent with previous studies conducted in short-term breast cancer survivors, which demonstrated that the link between depression and treatment toxicity was nonsignificant or inconsistent regarding chemotherapy or hormonotherapy [9,39-41]. Our results agree with previous studies regarding the absence of a link between long-term depression and initial cancer-related variables, such as tumor stage at diagnosis [40], tumor size, tumor histological type and node status [9]. Only the time since diagnosis was found to be inconsistently associated with long-term depression [40-43], and no link between these variables was found in our sample. The small range in time since diagnosis in our sample may explain this result. Previous studies support our results and tend to suggest that late treatment toxicity, initial chemoradiotherapy type and cancer-related variables have no or a minimal impact on late depression in LTBCS. These results are also consistent with early-stage breast cancer studies that found that objective cancer-related variables are not associated with depressive symptoms $[44,45]$.

The $19.2 \%$ significant depression prevalence rate observed in our study is comparable to or slightly higher than the prevalence reported in previous LTBCS studies that used the same HAD thresholds [46-48]. To our knowledge, our study includes survivors with the longest reported mean follow-up (time since the end of treatment $=8.1$ years). Our study confirms that although depression is common among patients with LTBCS, the reported rates of psychotropic medication use and psycho-oncological intervention are particularly low in this population. These results are consistent with the fact that among patients with cancer, depression is underdiagnosed by oncologists and is undertreated [11-13], although effective psychotherapeutic and pharmacological interventions exist in this field $[10,49]$. To deliver appropriate psycho-oncological care for depression, a close collaboration between psychiatric or psycho-oncological teams and oncological teams is needed.

Our study has some limitations. First, we assessed long-term depression using a selfadministered scale (the HAD), which was mainly designed to screen for, rather than diagnose, depression. Although the use of a concomitant structured psychiatric interview for depression would have been time consuming, it may have decreased the number of false positive or negative depression cases. To our knowledge, no study has assessed LTBCS-related depression with a structured interview using DSM-IV depression criteria. Our small sample size and the $56 \%$ participation rate limits the generalizability of our findings, though the participation rate was comparable to previous studies [40,47]. Breast cosmesis was not evaluated with depression, and the time between the two evaluations was one and a half years. Finally, we tested the association between depression and a large number of factors, thus increasing the risk for Type I errors (false positives).

Despite these limitations, our study shows that LTBCS-related depression is associated with some patients' perceptions of changes in cosmetic outcomes for the treated breast. We also show that depression in this population is not associated with late 
radiotherapy toxicity, initial chemoradiotherapy treatment type, or initial cancer-related variables. These results have two important practical implications. First, because depression is underdiagnosed [11-13], clinicians should pay attention to patients' perceptions of breast cosmetic outcomes and subjective aspects of body image, particularly breast largeness, because those factors can help clinicians screen for depression in this population. Second, long-term depression seems to correlate more strongly with alterations in some patientperceived body image variables than initial cancer-related variables or treatment toxicity in LTBCS. If confirmed, early alterations in patient body image could be an important target for psychotherapeutic intervention. Further prospective and longitudinal studies are warranted to delve further into the issue of depression-associated factors for LTBCS.

\section{ACKNOWLEDGMENTS}

We would like to thank Daniel Serin, Alain Fourquet, Jean-François Bosset, Noël Breteau, Gilles Body, David Azria and Olivier Le Floch, who recruited patients in the initial ARCOSEIN trial.

We thank Peter W. Naylor for revising initial version of the manuscript in English. We also thank American Journal Experts for editing the second version of the manuscript.

\section{REFERENCES}

1. Ferlay J, Shin HR, Bray F, Forman D, Mathers C, Parkin DM. Estimates of worldwide burden of cancer in 2008: GLOBOCAN 2008. Int J Cancer 2010;127:2893-2917.

2. Altekruse SF, Kosary CL, Krapcho M et al. (eds). SEER Cancer Statistics Review, 19752007, National Cancer Institute. Bethesda, MD, http://seer.cancer.gov/csr/1975_2007/, based on November 2009 SEER data submission, posted to the SEER web site, 2010.

3. Institut National du Cancer (INCa). La situation du cancer en France en 2009. Institut National du Cancer: Boulogne-Billancourt, 2009.

4. Rachet B, Maringe C, Nur U et al. Population-based cancer survival trends in England and Wales up to 2007: an assessment of the NHS cancer plan for England. Lancet Oncol 2009;10:351-369.

5. American Cancer Society. Cancer Facts and Figures 2010. American Cancer Society: Atlanta, 2010.

6. Bloom JR, Petersen DM, Kang SH. Multi-dimensional quality of life among long-term (5+ years) adult cancer survivors. Psychooncology 2007;16:691-706.

7. Bloom JR, Stewart SL, Chang S, Banks PJ. Then and now: quality of life of young breast cancer survivors. Psychooncology 2004;13:147-160.

8. Mols F, Vingerhoets AJ, Coebergh JW, van de Poll-Franse LV. Quality of life among long-term breast cancer survivors: a systematic review. Eur J Cancer 2005;41:2613-2619.

9. Burgess C, Cornelius V, Love S, Graham J, Richards M, Ramirez A. Depression and anxiety in women with early breast cancer: five year observational cohort study. BMJ 2005;330:702-705.

10. Fann J, Thomas-Rich AM, Katon WJ et al. Major depression after breast cancer: a review of epidemiology and treatment. Gen Hosp Psychiatry 2008;30:112-126.

11. Fallowfield L, Ratcliffe D, Jenkins V, Saul J. Psychiatric morbidity and its recognition by doctors in patients with cancer. Br J Cancer 2001;84:1011-1015.

12. Passik SD, Dugan W, McDonald MV, Rosenfeld B, Theobald DE, Edgerton S. Oncologists' recognition of depression in their patients with cancer. J Clin Oncol 1998;16:1594-1600.

13. Reich M, Lesur A, Perdrizet-Chevallier C. Depression, quality of life and breast cancer: a 
review of the literature. Breast Cancer Res Treat 2008;110:9-17.

14. Helms RL, O'Hea EL, Corso M. Body image issues in women with breast cancer. Psychol Health Med 2008;13:313-325.

15. White CA. Body image dimensions and cancer: a heuristic cognitive behavioural model. Psychooncology 2000;9:183-192.

16. Slade PD. What is body image? Behav Res Ther 1994;32:497-502.

17. Munshi A, Kakkar S, Bhutani R, Jalali R, Budrukkar A, Dinshaw KA. Factors influencing cosmetic outcome in breast conservation. Clin Oncol (R Coll Radiol) 2009;21:285-293.

18. Sneeuw KC, Aaronson NK, Yarnold JR et al. Cosmetic and functional outcomes of breast conserving treatment for early stage breast cancer. 1. Comparison of patients' ratings, observers' ratings, and objective assessments. Radiother Oncol 1992;25:153-159.

19. Carver CS, Pozo-Kaderman C, Price AA et al. Concern about aspects of body image and adjustment to early stage breast cancer. Psychosom Med 1998;60:168-174.

20. Irwig L, Bennetts A. Quality of life after breast conservation or mastectomy: a systematic review. Aust N Z J Surg 1997;67:750-754.

21. Al-Ghazal SK, Fallowfield L, Blamey RW. Patient evaluation of cosmetic outcome after conserving surgery for treatment of primary breast cancer. Eur J Surg Oncol 1999;25:344346.

22. Sneeuw KC, Aaronson NK, Yarnold JR et al. Cosmetic and functional outcomes of breast conserving treatment for early stage breast cancer. 2. Relationship with psychosocial functioning. Radiother Oncol 1992;25:160-166.

23. Al-Ghazal SK, Fallowfield L, Blamey RW. Does cosmetic outcome from treatment of primary breast cancer influence psychosocial morbidity? Eur J Surg Oncol 1999;25:571573.

24. Waljee JF, Hu ES, Ubel PA, Smith DM. Newman LA, Alderman AK. Effect of esthetic outcome after breast-conserving surgery on psychosocial functioning and quality of life. $J$ Clin Oncol 2008;26:3331-3337.

25. Toledano A, Bollet MA, Fourquet A et al. Does concurrent radiochemotherapy affect cosmetic results in the adjuvant setting after breast-conserving surgery? Results of the ARCOSEIN multicenter, Phase III study: patients' and doctors' views. Int J Radiat Oncol Biol Phys 2007;68:66-72.

26. Senkus-Konefka E, Jassem J. Complications of breast-cancer radiotherapy. Clin Oncol ( $R$ Coll Radiol) 2006;18:229-235.

27. Calais G. Radiation and concomitant chemotherapy after surgery for breast cancer: Arcosein study. Cancer Radiother 1998;2:469-474.

28. Toledano A, Azria D, Garaud P et al. Phase III trial of concurrent or sequential adjuvant chemoradiotherapy after conservative surgery for early-stage breast cancer: final results of the ARCOSEIN trial. J Clin Oncol 2007;25:405-410.

29. Toledano A, Garaud P, Serin D et al. Concurrent administration of adjuvant chemotherapy and radiotherapy after breast-conserving surgery enhances late toxicities: long-term results of the ARCOSEIN multicenter randomized study. Int J Radiat Oncol Biol Phys 2006;65:324-332.

30. Hoeller U, Kuhlmey A, Bajrovic A et al. Cosmesis from the patient's and the doctor's view. Int J Radiat Oncol Biol Phys 2003;57:345-354.

31. Fehlauer F, Tribius S, Höller U et al. Long-term radiation sequelae after breast-conserving therapy in women with early-stage breast cancer: an observational study using the LENTSOMA scoring system. Int J Radiat Oncol Biol Phys 2003;55:651-658.

32. Hoeller U, Tribius S, Kuhlmey A, Grader K, Fehlauer F, Alberti W. Increasing the rate of late toxicity by changing the score? A comparison of RTOG/EORTC and LENT/SOMA scores. Int J Radiat Oncol Biol Phys 2003;55:1013-1018. 
33. Mornex F, Pavy JJ, Denekamp J, Bolla M. Scoring system of late effects of radiations on normal tissues: the SOMA-LENT scale. Cancer Radiother 1997;1:622-668.

34. Zigmond AS, Snaith RP. The hospital anxiety and depression scale. Acta Psychiatr Scand 1983;67:361-370.

35. Razavi D, Delvaux N, Farvacques C, Robaye E. Screening for adjustment disorders and major depressive disorders in cancer in-patients. Br J Psychiatry 1990;156:79-83.

36. Bjelland I, Dahl AA, Haug TT, Neckelmann D. The validity of the Hospital Anxiety and Depression Scale. An updated literature review. J Psychosom Res 2002;52:69-77.

37. Alexander S, Palmer C, Stone PC. Evaluation of screening instruments for depression and anxiety in breast cancer survivors. Breast Cancer Res Treat 2010;122:573-578.

38. Beck AT. The evolution of the cognitive model of depression and its neurobiological correlates. Am J Psychiatry 2008;165:969-977.

39. Casso D, Buist DS, Taplin S. Quality of life of 5-10 year breast cancer survivors diagnosed between age 40 and 49. Health Qual Life Outcomes 2004;2:25-33.

40. Kim S, Son B, Hwang S et al. Fatigue and depression in disease-free breast cancer survivors: prevalence, correlates, and association with quality of life. J Pain Symptom Manage 2008;35:644-655.

41. Perkins EA, Small BJ, Balducci L, Extermann M, Robb C, Haley WE. Individual differences in well-being in older breast cancer survivors. Crit Rev Oncol Hematol 2007;62:74-83.

42. Carver CS, Antoni MH. Finding benefit in breast cancer during the year after diagnosis predicts better adjustment 5 to 8 years after diagnosis. Health Psychol 2004;23:595-598.

43. Carver CS, Smith RG, Antoni MH, Petronis VM, Weiss S, Derhagopian RP. Optimistic personality and psychosocial well-being during treatment predict psychosocial well-being among long-term survivors of breast cancer. Health Psychol 2005;24:508-516.

44. Bardwell WA, Natarajan L, Dimsdale JE et al. Objective cancer-related variables are not associated with depressive symptoms in women treated for early-stage breast cancer. $J$ Clin Oncol 2006;24:2420-2427.

45. Chen X, Zheng Y, Zheng W et al. Prevalence of depression and its related factors among Chinese women with breast cancer. Acta Oncol 2009;48:1128-1136.

46. Hodgkinson K, Butow P, Hunt GE, Pendlebury S, Hobbs KM, Wain G. Breast cancer survivors' supportive care needs 2-10 years after diagnosis. Support Care Cancer 2007; 15:515-523.

47. Hopwood P, Sumo G, Mills J, Haviland J, Bliss JM, START Trials Management Group. The course of anxiety and depression over 5 years of follow-up and risk factors in women with early breast cancer: results from the UK Standardisation of Radiotherapy Trials (START). Breast 2010;19:84-91.

48. Mehnert A, Koch U. Psychological comorbidity and health-related quality of life and its association with awareness, utilization, and need for psychosocial support in a cancer register-based sample of long-term breast cancer survivors. J Psychosom Res 2008;64:383-391.

49. Naaman SC, Radwan K, Fergusson D, Johnson S. Status of psychological trials in breast cancer patients: a report of three meta-analyses. Psychiatry 2009;72:50-69. 


\section{TABLES}

Table 1. Characteristics of our study population $(n=120)$

Mean $( \pm$ SD)

Number of patients $(\%)$

\section{Sociodemographic characteristics}

Age at the end of treatment (years)

$50.2( \pm 8.1)$

Age at the time of our study (years)

$58.3( \pm 8.2)$

Time since the end of treatment (years)

$8.1( \pm 1.3)$

Menopausal status (yes)

$54(45 \%)$

Marital status (at the end of treatment)

Married or in a relationship

Single

\section{Cancer-related variables}

Tumor stage at diagnosis

T0

$5(4.2 \%)$

$\mathrm{T} 1$

$69(57.5 \%)$

$43(35.8 \%)$

$0(0 \%)$

T3

$1(0.8 \%)$

Node status (positive)

$79(65.8 \%)$

Tumor dimension ( $\mathrm{mm}$ )

$19.2( \pm 8.1)$

Histological type

Ductal

(75\%)

Lobular

$18(15 \%)$

Other

$12(10 \%)$

\section{Type of treatment}

Surgery type

Tumorectomy

$105(88.2 \%)$

Quadrantectomy

$15(12.6 \%)$

Administration of chemoradiotherapy

Concurrent

$61(50.8 \%)$

Sequential

$59(49.2 \%)$

Hormonotherapy (yes)

$55(45.8 \%)$

\section{Significant late toxicity symptoms}

At least one toxicity symptom

$63(53 \%)$

Pain

$18(15 \%)$

Edema

$1(0.8 \%)$

Fibrosis

$17(14.2 \%)$

Telangiectasia

$17(14.2 \%)$ 
Arm lymphedema

Atrophy or retraction

Ulcer
$4(3.3 \%)$

$42(35 \%)$ 
Table 2. Patient and doctor ratings of breast cosmetic outcomes

\begin{tabular}{|c|c|c|c|c|c|c|c|}
\hline & & $\mathrm{n}$ & $\mathrm{S} 1$ & $\mathrm{~S} 2$ & $\mathrm{~S} 3$ & $\mathrm{~S} 4$ & S5 \\
\hline \multirow{2}{*}{$\begin{array}{l}\text { Overall cosmetic } \\
\text { satisfaction }\end{array}$} & Patients & 120 & $33(27.5 \%)$ & $39(32.5 \%)$ & $40(33.3 \%)$ & $6(5 \%)$ & $2(1.7 \%)$ \\
\hline & Doctors & 120 & $8(6.7 \%)$ & $48(40 \%)$ & $29(24.2 \%)$ & $22(18.3 \%)$ & $13(10.8 \%)$ \\
\hline \multirow[t]{2}{*}{ Visibility of the scar } & Patients & 119 & $23(19.35 \%)$ & $57(47.9 \%)$ & $23(19.35 \%)$ & $13(10.9 \%)$ & $3(2.5 \%)$ \\
\hline & Doctors & 120 & $25(20.8 \%)$ & $44(36.7 \%)$ & $30(25 \%)$ & $14(11.7 \%)$ & $7(5.8 \%)$ \\
\hline $\begin{array}{l}\text { Change in skin } \\
\text { pigmentation }\end{array}$ & Patients & 118 & $80(67.8 \%)$ & $27(22.9 \%)$ & $9(7.6 \%)$ & $2(1.7 \%)$ & 0 \\
\hline Breast deformed & Patients & 117 & $42(35.9 \%)$ & $49(41.9 \%)$ & $16(13.6 \%)$ & $9(7.7 \%)$ & $1(0.9 \%)$ \\
\hline Breast larger & Patients & 116 & $76(65.5 \%)$ & $26(22.4 \%)$ & $13(11.2 \%)$ & $1(0.9 \%)$ & 0 \\
\hline Breast smaller & Patients & 114 & $41(36 \%)$ & $43(37.7 \%)$ & $12(10.5 \%)$ & $15(13.2 \%)$ & $3(2.6 \%)$ \\
\hline Breast firmness & Patients & 120 & $62(51.7 \%)$ & $32(26.7 \%)$ & $14(11.7 \%)$ & $11(9.1 \%)$ & $1(0.8 \%)$ \\
\hline Nipple displacement & Patients & 113 & $81(71.7 \%)$ & $19(16.8 \%)$ & $7(6.2 \%)$ & $5(4.4 \%)$ & $1(0.9 \%)$ \\
\hline
\end{tabular}

For overall cosmetic satisfaction: Score $1(\mathrm{~S} 1)=$ excellent; $\mathrm{S} 2=$ good; $\mathrm{S} 3=$ satisfying; $\mathrm{S} 4=$ bad; $\mathrm{S} 5=$ very bad For all other dimensions: Score $1(\mathrm{~S} 1)=$ not at all; $\mathrm{S} 2=\mathrm{a}$ little; $\mathrm{S} 3=$ moderate; $\mathrm{S} 4=$ much; $\mathrm{S} 5=$ very much 
Table 3. Polytomous logistic regression analysis of significant depression predictors Standard

Estimate error $\quad \mathrm{Z} \quad p$-value

\section{Probable depression vs. no depression}

Patient ratings of breast cosmetic outcomes

Overall cosmetic satisfaction*

$-.66$

Visibility of the scar*

$-.64$

$-1.65$

.10

Change in skin pigmentation*

$-1.12$

$-1.71$

.09

Breast largeness*

$-.98$

.50

$-2.22$

.03

Breast deformation*

1.14

.47

$-2.07$

.04

Breast size

.03

.49

$-2.36$

.02

Breast firmness*

.10

.43

.07

.94

Nipple displacement*

$-.25$

Nipple displacement

.41

$-.61$

Doctor ratings of breast cosmetic outcomes

Overall cosmetic satisfaction*

$\begin{array}{llll}-.75 & .36 & -2.08 & .04 \\ -.62 & .38 & -1.61 & .11\end{array}$

Visibility of the scar*

$-6$

Probable depression vs. possible depression

Patient ratings of breast cosmetic outcomes

Overall cosmetic satisfaction

$-.57$

Visibility of the scar*

$-.76$

.46

$-1.65$

Change in skin pigmentation*

$-1.10$

.62

$-1.77$

.08

Breast largeness*

$-.45$

.54

$-.83$

Breast deformation*

$-.88$

.53

$-1.65$

.10

Breast size

.11

.48

.23

.82

Breast firmness

$-.12$

.47

$-.25$

.80

Nipple displacement*

$-.29$

.50

$-.58$

.56

Doctor ratings of breast cosmetic outcomes

Overall cosmetic satisfaction*

Visibility of the scar*

$-.34$

.43

$-.80$

All logistic regression analyses were adjusted for age, tumor stage at diagnosis, time since the end of treatment and marital status. 
* indicates that the corresponding regression analysis also showed a significant and independent effect for being single without first-order interactions.

\section{FIGURES}

Figure 1. Study flow chart

\section{ARCOSEIN initial population ( $\mathrm{T} 1$ assessment)}

716 patients with Stage I to II breast cancer treated with breast-conserving surgery with axillary dissection

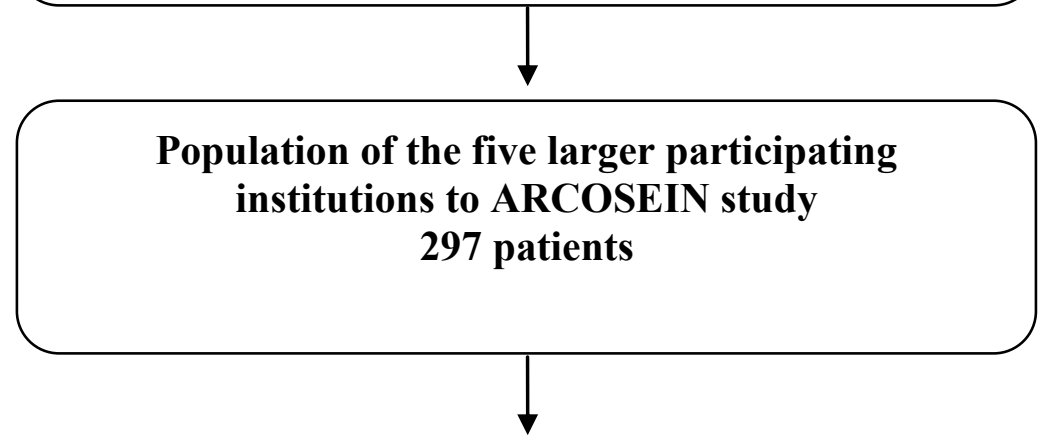

Patients agreed to participate to a follow up visit that focused on late toxicity and cosmetic evaluation = eligible population ( $\mathrm{T} 2$ assessment) 214 patients

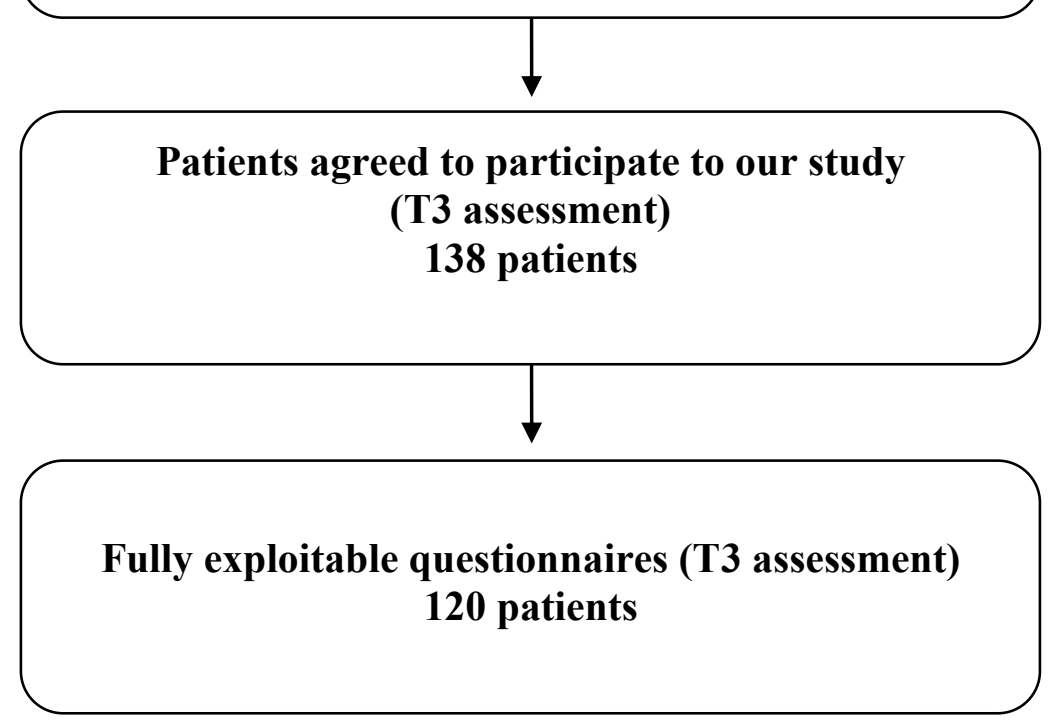

